\title{
Experimental Investigation on the Vacuum Arc Behaviors of the Axial Magnetic Field (AMF) Electrode with Single Coil Structure*
}

\author{
Shaoyong CHENG, Shixin XIU, Jimei WANG and Zhengchao SHEN \\ Department of electrical engineering Xi'an Jiaotong University, Xi'an 710049, China \\ (Received July 14, 2006, Accepted April 7, 2007)
}

In this paper, the influence of arc current on vacuum arc behaviors of a new AMF electrode with single coil structure was investigated at long gap distance of $40 \mathrm{~mm}$. A high-speed charge couple device (CCD) video camera was used to observe the arc behaviors. Two groups of arc modes were featured: 1) diffuse arc modes including multi-cathode spots arc, high current diffuse arc and high current diffuse column arc. 2) constricted arc modes including anode plasma jet with local concentration of many cathode spots and group of cathode spots (APJS), anode plasma jet with local concentration of many cathode spots, anode and cathode plasma jets (APJ), and intense arc mode. The vacuum arc behaviors under different amplitude of arc current were researched.

\section{Introduction}

The research on interrupting characteristics in vacuum at long gap distance is important to develop the high voltage and large capacity vacuum interrupter. The vacuum arc modes and their transition have great influence on the interrupting characteristics in vacuum at long gap distance. Many scholars have investigated vacuum arc modes transition under different conditions ${ }^{1-8}$. But the investigation on the arc modes transition has not been profoundly researched at long gap distance $40 \mathrm{~mm}$.

To study the vacuum arc modes and their transition, we will have a brief review upon various vacuum arc modes as follows:

1) Diffuse arc modes, which include multi-cathode spot $\operatorname{arc}^{1)}$, low current diffuse $\operatorname{arc}^{7)}$, high-current diffuse $\operatorname{arc}^{1,7)}$, high current diffuse column $\operatorname{arc}^{1)}$, and transient foot-point mode ${ }^{6}$.

2) Constricted arc modes, which include anode jet and anode $\operatorname{spot}^{8)}$, anode spot mode ${ }^{8)}$, anode plasma jet with local concentration of many cathode spots (LCMCS) and group of autonomous cathode spots (APJS), anode plasma jet with LCMCS (APJ), anode and cathode plasma jets $\left.(\mathrm{ACPJ})^{7}\right)$; and intense arc mode ${ }^{5) / c o n s t r i c t e d ~ c o l u m n ~ a n d ~ j e t ~ c o l u m n ~}{ }^{8)} /$ column $\operatorname{arc}^{7)}$.

In this paper, the AMF electrode with single coil structure for high voltage vacuum interrupter was designed. And the influence of arc current on arc behaviors of a new AMF electrode with single coil structure was investigated at long gap distance of $40 \mathrm{~mm}$.

\section{Experimental circuit}

As shown in Fig. 1, two AMF electrodes $(\phi 50 \mathrm{~mm})$ with single coil structure were amounted in the demountable vacuum chamber (DVC). The position of lower

\footnotetext{
* Presented at ISDEIV 2006, Matsue, Japan, September 25-29, 2006
}

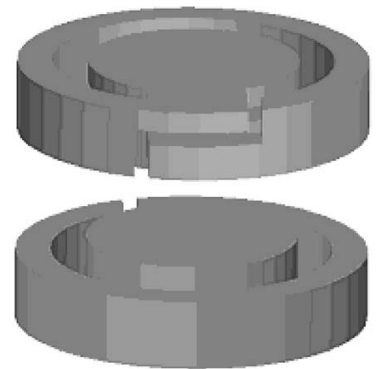

Fig. 1 The configuration of single coil type axial magnetic field electrode.

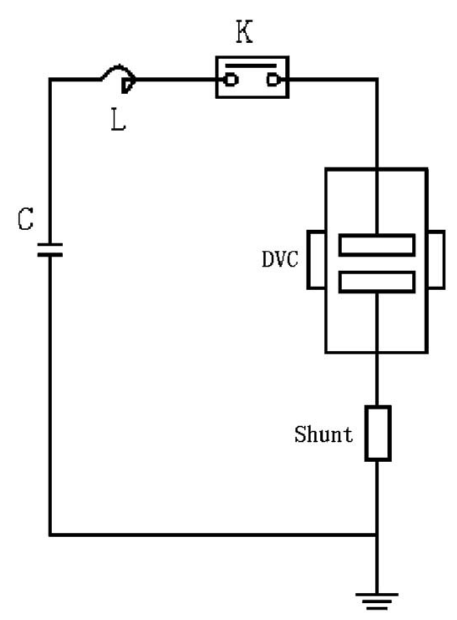

Fig. 2 A schematic of test circuit for vacuum arc appearance observation. K-switch, DVC-demountable vacuum chamber, Shunt-shunt resistance of $80 \mu \Omega$. Current frequency is $50 \mathrm{~Hz}$.

electrode could be adjusted to change the gap distance. A trigger needle made of tungsten inside lower electrode was used for ignition.

As shown in Fig. 2, the experimental current was provided by a single frequency $\mathrm{L}-\mathrm{C}$ oscillating circuit. The capacitance $\mathrm{C}$ was $0.0168 \mathrm{~F}$. And the inductance $\mathrm{L}$ was 
$0.603 \mathrm{mH}$. The frequency of the L-C oscillating circuit was $50 \mathrm{~Hz}$. The shunt resistance was $80 \mu \Omega$.

For the visual investigation of vacuum arc behaviors, a high-speed charge couple device (CCD) video camera was used. The recording velocity of the high-speed CCD video camera was 4000 frames/second. The exposure time of the high-speed CCD video camera was $0.25 \mathrm{~ms}$. Arc current was collected by a shunt and arc voltage was measured by a high voltage probe. The arc voltage and arc current signals were sent to an oscilloscope for recording.

\section{Experimental results and discussion}

The amplitude of arc current is $2.8 \mathrm{kA}$. The arc behaviors are presented in Fig. 3. From the initiation moment, the discharge process started. At $0.75 \mathrm{~ms}$, the anode spots covering the whole surface of anode had formed. From which anode plasma jet emerged. And there were some cathode spots on the cathode. Soon after that, the anode plasma jet became stronger. And several grouped cathode spots almost occupied the entire surface of cathode at $1.5 \mathrm{~ms}$. Dim glow of cathode spots filled with the inter-electrode gap. The arc was denoted APJS. At $3.5 \mathrm{~ms}$, cathode spots occupied the entire surface of



$0 \mathrm{~ms}$

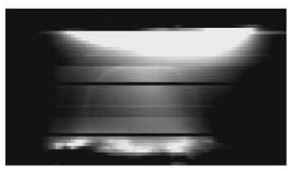

$1.5 \mathrm{~ms}$

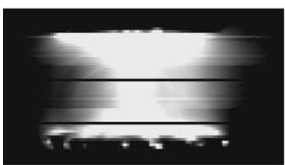

$4.5 \mathrm{~ms}$

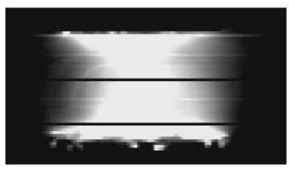

$5.5 \mathrm{~ms}$

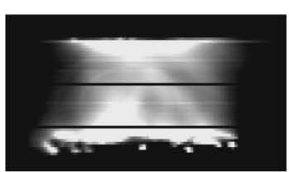

$6.75 \mathrm{~ms}$



$9.25 \mathrm{~ms}$

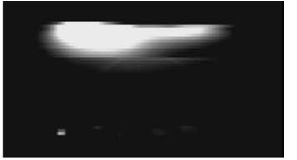

$0.75 \mathrm{~ms}$

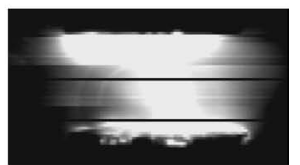

$3.5 \mathrm{~ms}$

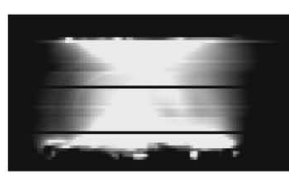

$5.0 \mathrm{~ms}$



$6.25 \mathrm{~ms}$

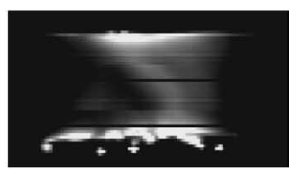

$8.25 \mathrm{~ms}$



$9.75 \mathrm{~ms}$
Fig. 3 The amplitude of arc current is $2.8 \mathrm{kA}$. The gap distance is $40 \mathrm{~mm}$. The upper electrode is anode. The lower electrode is cathode. The white part is vacuum arc cathode. And there was a central plasma core from anode to cathode that was much brighter than the arc in periphery. This arc mode was high current diffuse arc. In a short time, the high current diffuse column arc was unstable. The intensity and position of anode or cathode spots continuously varied. And the central plasma core also changed. At $4.5 \mathrm{~ms}$, the high current diffuse arc became stable. This arc mode maintained up to $9.25 \mathrm{~ms}$. From $6.25 \mathrm{~ms}$ to $9.75 \mathrm{~ms}$, the arc column began to become diffuse. Some single cathode spots could be resolved according to the photographs at $6.25 \mathrm{~ms}, 6.75$ $\mathrm{ms}, 8.25 \mathrm{~ms}$ and $9.25 \mathrm{~ms}$. After $9.75 \mathrm{~ms}$, only some single cathode spots were visible. The anode is completely passive. The arc transits into a multi-cathode spot $\operatorname{arc}^{1)}$.

With the amplitude of arc current increasing to 5.7 kA, the arc behaviors are presented in Fig. 4. After the discharge started, the anode plasma jet occurred near the anode edge at $0.5 \mathrm{~ms}$. Some cathode spots covered the entire surface of cathode. Soon after that, the anode spots spread at the edge and side of anode at $0.75 \mathrm{~ms}$. At $1.5 \mathrm{~ms}$ the anode plasma jet and the cathode plasma jet were all severe. No single cathode spot could be resolved. At $3.0 \mathrm{~ms}$ the arc column formatted in the inter-electrode gap. From $4.0 \mathrm{~ms}$ to $7.0 \mathrm{~ms}$, the arc maintained a high

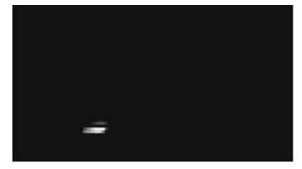

$0 \mathrm{~ms}$

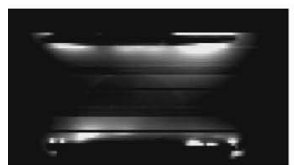

$0.75 \mathrm{~ms}$



$3.0 \mathrm{~ms}$

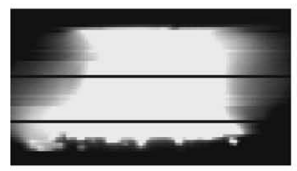

$5.0 \mathrm{~ms}$

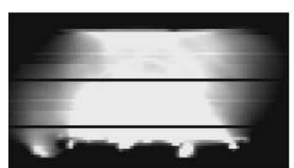

$7.25 \mathrm{~ms}$

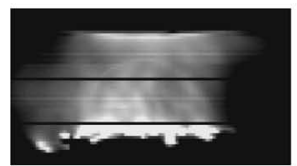

$8.25 \mathrm{~ms}$

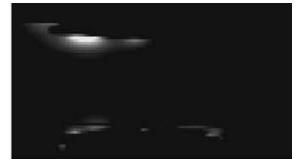

$0.5 \mathrm{~ms}$

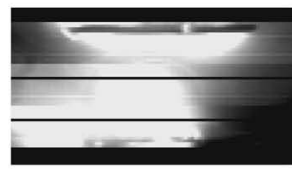

$1.5 \mathrm{~ms}$

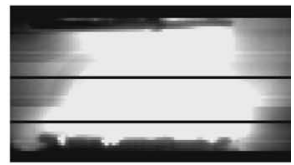

$4.0 \mathrm{~ms}$



$7.0 \mathrm{~ms}$

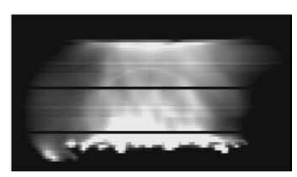

$8.0 \mathrm{~ms}$



$9.5 \mathrm{~ms}$
Fig. 4 The amplitude of arc current is $5.7 \mathrm{kA}$. The gap distance is $40 \mathrm{~mm}$. The upper electrode is anode. The lower electrode is cathode. The white part is vacuum arc 


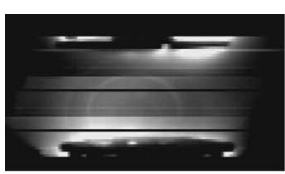

$0.5 \mathrm{~ms}$

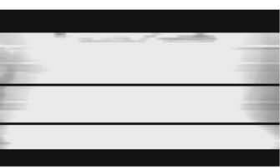

$2.5 \mathrm{~ms}$



$4.5 \mathrm{~ms}$

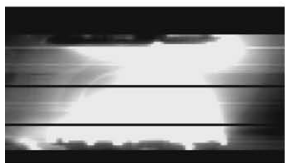

$6.5 \mathrm{~ms}$

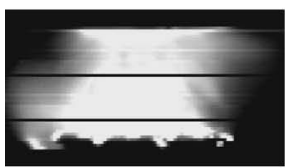

$7.75 \mathrm{~ms}$

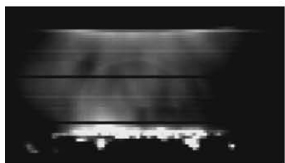

$9.0 \mathrm{~ms}$

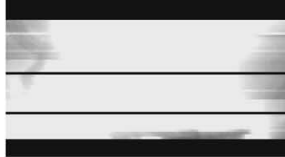

$1.5 \mathrm{~ms}$

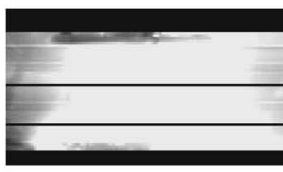

$3.5 \mathrm{~ms}$

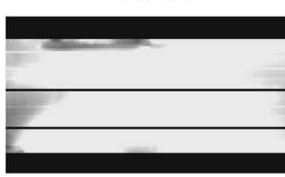

$5.0 \mathrm{~ms}$

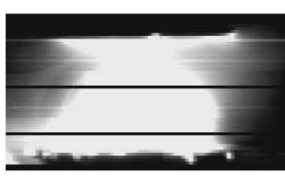

$7.0 \mathrm{~ms}$

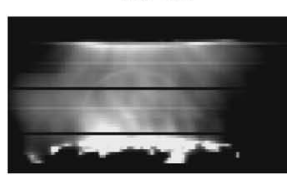

$8.5 \mathrm{~ms}$

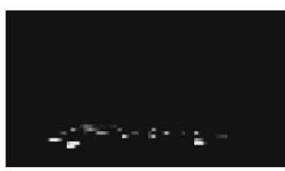

$9.5 \mathrm{~ms}$
Fig. 5 The amplitude of arc current is $8.0 \mathrm{kA}$. The gap distance is $40 \mathrm{~mm}$. The upper electrode is anode. The lower electrode is cathode. The white part is vacuum arc

current diffuse column $\operatorname{arc}^{1)}$. After $7.0 \mathrm{~ms}$, the arc column gradually vanished at $7.25 \mathrm{~ms}$. At $8.0 \mathrm{~ms}$ the anode was still active. The arc column became diffuse. At $8.25 \mathrm{~ms}$ the arc column became entirely diffuse. The anode was still active. At $9.5 \mathrm{~ms}$ the anode was almost completely passive. The arc column disappeared. Some single cathode spots could be recognized. From this moment to current zero, the arc exhibited a multi-cathode spot $\operatorname{arc}^{1)}$.

At peak arc current of $8.0 \mathrm{kA}$, the arc behaviors are presented in Fig. 5. After the discharge started, the anode or cathode spots occurred at the edge or side of electrode at $0.5 \mathrm{~ms}$. At $1.5 \mathrm{~ms}$, the inter-electrode gap was completely filled with bright glow of the arc column. At this moment, the arc modes transited into a high current diffuse column $\operatorname{arc}^{1)}$, which exited up to $6.5 \mathrm{~ms}$. At $6.5 \mathrm{~ms}$, the concentration of arc column near the anode surface appeared. The intense arc mode formed. Up to $7.75 \mathrm{~ms}$, the arc became diffuse. The arc column gradually disappeared from the peripheral to the center of arc column. At $8.5 \mathrm{~ms}$, the arc column became completely diffuse. At $9.5 \mathrm{~ms}$ only some single cathode spots distributed on the surface of cathode. The arc exhibits a multi-cathode spot $\operatorname{arc}^{1)}$.
While the amplitude of arc current was $2.8 \mathrm{kA}$, the arc experienced APJS ${ }^{7)}$ from $0.75 \mathrm{~ms}$ to $3.5 \mathrm{~ms}$, a high current diffuse arc and a multi-cathode spot $\operatorname{arc}^{1)}$ from 3.5 $\mathrm{ms}$ to current zero. With the amplitude of arc current increasing to $5.7 \mathrm{kA}$, the arc experienced APJS ${ }^{7)}$ from 0.5 $\mathrm{ms}$ to $1.5 \mathrm{~ms}$, APJ ${ }^{7)}$ from $1.5 \mathrm{~ms}$ to $3.0 \mathrm{~ms}$ and diffuse arc from $3.0 \mathrm{~ms}$ to arc current zero. At last, while the amplitude of arc current was $8.0 \mathrm{kA}$, the arc experiences $\mathrm{APJS}^{7}$ ) from $0.5 \mathrm{~ms}$ to $1.5 \mathrm{~ms}$, a high current diffuse column $\operatorname{arc}^{1)}$ from $1.5 \mathrm{~ms}$ to $6.5 \mathrm{~ms}$, intense arc mode ${ }^{6}$ from $6.5 \mathrm{~ms}$ to $7.75 \mathrm{~ms}$, and a high current diffuse arc and a multi-cathode spot $\operatorname{arc}^{1)}$ from $7.75 \mathrm{~ms}$ to current zero. Although during the stage of a high current diffuse column $\operatorname{arc}^{1}$, one part of the vacuum arc overflowed the inter-electrode gap. But the distribution of vacuum arc on the surface of anode or cathode was still uniform. And the arc column in the inter-electrode gap still kept diffuse. After $6.5 \mathrm{~ms}$, the arc transited into intense arc mode ${ }^{6}$. The concentration of arc column near the anode occurred up to $7.75 \mathrm{~ms}$. After $7.75 \mathrm{~ms}$ the arc transited into a high current diffuse $\operatorname{arc}^{1)}$. The APJS and APJ ${ }^{7)}$ were unstable because the position and intensity of anode or cathode spots always varied and would change into other arc modes with arc current increasing, according to the arc photographs while amplitude of arc current $2.75 \mathrm{kA}, 5.7 \mathrm{kA}$ and $8.0 \mathrm{kA}$. The vacuum arc could be kept in diffuse arc modes in most of time during semiwave of current flow, which would result in successful current interruption.

Because the condition in commercial interrupter is better than that in demountable chamber, the current interruption capability can be better in the practical application than in the demountable chamber by the AMF electrode with single coil structure under diameter of $50 \mathrm{~mm}$ and gap distance of $40 \mathrm{~mm}$. The test results can provide reference to design the high voltage vacuum interrupter in practical application using the AMF electrode with single coil structure.

\section{Summary}

In this paper, the influence of arc current on arc behaviors of a new AMF electrode with single coil structure was investigated at long gap distance of $40 \mathrm{~mm}$. Two groups of arc modes were founded: 1) diffuse arc modes including multi-cathode spot arc, high current diffuse arc and high current diffuse column $\operatorname{arc}^{1)}$. 2) constricted arc modes including APJS, APJ ${ }^{7)}$ and intense arc mode ${ }^{6}$. With the amplitude of arc current increasing, the arc modes developed sequentially from the high current diffuse arc, high current diffuse column $\operatorname{arc}^{1)}$ and intense arc mode ${ }^{6}$. When the amplitude of arc current is $8.0 \mathrm{kA}$, the concentration of arc column near the anode existed in a short duration between $6.5 \mathrm{~ms}$ and $7.75 \mathrm{~ms}$. The vacuum arc could be kept in diffuse arc modes in most of time during semi-wave of current flow. The current interruption capability could be better in the practical application than in the demountable chamber by the AMF electrode with single coil structure under diameter of 50 $\mathrm{mm}$ and gap distance of $40 \mathrm{~mm}$. The test results can provide reference to design the high voltage vacuum inter- 
rupter using the AMF electrode with single coil structure.

\section{Acknowledgement}

This work was supported by National Natural Science Foundation of China under Project 50477024.

\section{References}

1) M. B. Schulman: IEEE Transaction On Plasma Science., 28(2) (2000) 443 .

2) Zongqian Shi, Shenli Jia, Jun Fu, et al.: IEEE Transaction On Plasma Science, 31(2) (2003) 289.
3) W. Shang, E. Dullni, H. Fink, et al.: IEEE Transaction On Plasma Science, 31(5) (2003) 923.

4) M. Lindmayer and K. Steinke: IEEE 21th Int. Symp. On Discharges and Electrical Insulation in Vacuum, Berkeley, 2004 p. 1.

5) R. L. Boxman, P. J. Martin, D. M. Sers, et al.: Handbook of vacuum arc science and technology (ParkRidge, NJ: Noyes, 1995) $\mathrm{p}$. 308.

6) H. C. Miller: IEEE Transactions On Plasma Science., 4(4) (1997) 382.

7) Z. Zalucki Z and J. Janiszewski: IEEE Transactions On Plasma Science., 27(4) (1999) 991.

8) M. B. Schulman, P. G. Slade and J. V. R. Heberlein: IEEE Transaction On Comp. Hybrids Manufact Technol., 16 (1993) 180. 